ARCHIVO ESPAÑOL DE ARTE, LXXIX, 316

OCTUBRE-DICIEMBRE, pp. 355-370, 2006

ISSN: 0004-0428

\title{
NOTICIAS DE FRANCISCO DE HERRERA EL VIEJO EN MADRID Y DEL RETABLO MAYOR DEL COLEGIO DE SAN BASILIO, DE SEVILLA
}

\author{
POR \\ Francisco J. Cornejo \\ Profesor contratado doctor de la Universidad de Sevilla
}

\begin{abstract}
En este artículo se dan a conocer documentos que certifican la presencia en Madrid del pintor Francisco de Herrera el Viejo en 1647 y 1648. Además, se aportan importantes novedades acerca del retablo de San Basilio, de Sevilla: las medidas de su arquitectura; el retraso en casi diez años de su instalación y pago al pintor; y, sobre todo, las tres pinturas localizadas - un Niño Jesús, de la puerta del sagrario y los retratos de San Basilio el Mayor y de Santa Eumelia, padres de San Basilio - que continúan insertas en un fragmento del retablo original.
\end{abstract}

Palabras clave: Pintura española; S. XVII; Francisco de Herrera el Viejo; Colegio de San Basilio de Sevilla.

Documents are presented here attesting to the presence of the painter Francisco de Herrera el Viejo in Madrid between 1647 and 1648. Likewise, important new information concerning the altarpiece of San Basilio in Seville is brought to light: the measurements of the architectural structure, the delay of almost ten years in its installation and payment to the artist; and, above all, the three paintings now located - a Christ Child from the door of the ciborium, and the portraits of Saint Basil the Great and Saint Eumelia, parents of Saint Basil - still attached to a fragment of the original alterpiece.

Key words: Spanish painting; Francisco de Herrera el Viejo (the Elder); Colegio de San Basilio in Seville.

Los estudiosos que se han ocupado de la vida y obra de Francisco de Herrera el Viejo, coinciden en señalar que el pintor sevillano, tras décadas de actividad en su ciudad natal, se trasladó a Madrid, lugar donde continuó ejerciendo su oficio hasta el momento de su fallecimiento. Sin embargo, hay entre ellos notables diferencias a la hora de datar momentos tan importantes como el de la llegada del artista a la corte o la fecha de su muerte: Antonio Palomino dice que "pasó" a la villa de Madrid "por el año de 1640" y que "murió en esta corte en el año de 1656 y está enterrado en la parroquial de San Ginés"; para Ceán Bermúdez, "partió a Madrid el [año] de [16]50, donde residió con crédito hasta el de [16]56, en que falleció"; Thacher comparte la fecha de llegada de 1640 pero propone 
la de 1657 para el fallecimiento; y Martínez Ripoll, finalmente, acepta la fecha de 1650 para el paso a Madrid y parece decantarse por la de 1654 para la de su óbito ${ }^{1}$. Pero la realidad es que, a pesar de todas estas declaraciones y suposiciones, hasta la fecha, no se conocía ninguna documentación fiable relativa al periodo madrileño de Herrera el Viejo ni, tampoco, han sido localizadas las obras pictóricas que los tratadistas le venían adjudicando a su etapa madrileña²

Afortunadamente, la localización en un archivo sevillano de interesantes documentos relativos al retablo mayor del Colegio de San Basilio, entre los que se hayan dos cartas de poder que el pintor otorgó ante sendos escribanos madrileños, vienen a aportar algo de luz a este incierto periodo de la vida del artista. Ambas cartas son sucesivas autorizaciones para reclamar y cobrar en Sevilla una cantidad que se le adeuda por el trabajo realizado en el citado retablo que (junto a otros papeles, como se verá más adelante) muestran como, a diferencia de lo que se venía suponiendo, el retablo basilio no quedó definitivamente instalado con todas sus pinturas hasta el año de 1647: es decir, casi diez años después de ser contratado 3 .

El primero de los documentos fue otorgado "en la Villa de Madrid a dos días del mes de julio de mil y seiscientos y cuarenta y siete años" ante Andrés de Pineda, escribano del rey, siendo testigos Marcos Serrano, Alfonso Pérez y Alfonso Gómez, "estantes en Madrid”, y comienza así:

Sepan quantos esta carta vieren, como yo, Francisco de Herrera y Aguilar, maestro pintor de ymaginería, vezino de la ciudad de Seuilla, residente en esta Corte, otorgo y conosco por esta pressente carta que doi y otorgo todo mi poder cumplido y bastante, como de derecho se requiere y es nescessario, a Juan de Herrera y Aguilar, mi hermano, vezino de la dicha ciudad de Seuilla, y cosmógrafo de la Casa de la Contratassión de la dicha Ciudad, espeçialmente para que por mí y en mi nombre, y repressentando mi perssona, pueda pedir y demandar, resçiuir, hauer y cobrar en juiçio y fuera dél, del mayordomo y hermanos de la cofradía de la Misericordia de la dicha ciudad de Seuilla, y de las demás personas a cuyo cargo eso fuere, la paga de duçientos ducados, poco más o menos, que se me deuen de resto de la pintura que hiçe en el Convento del señor San Bassilio de la dicha ciudad que es a cargo, la paga dello, de los sussodichos... [siguen las fórmulas habituales] ${ }^{4}$

1 Palomino [de Castro y Velasco], Antonio [Acisclo]: Vidas [“El Parnaso Español Pintoresco Laureado”, en Museo pictórico y escala óptica (1715-1724)], ed. Nina Ayala Mallory, Madrid, Alianza, 1986, pp. 143-145. CEÁn BERMÚDEZ, Juan Agustín: Diccionario histórico de los más ilustres profesores de las Bellas Artes [ed. facsímil: Madrid, Viuda de Ibarra, 1800], Tres Cantos, Istmo, 2001, t. II, pp. 274-279. THACHER, John S.: "The paintings of Francisco de Herrera, the Elder", The Art Bulletin, vol. XIX, n 3, september 1937, pp. 325-380. MARTínez RIPOLL, Antonio: Francisco de Herrera "el Viejo", Sevilla, Diputación Provincial, 1978. Tanto Palomino como Ceán siguen la noticia de la fecha de la muerte y lugar de enterramiento de Herrera recogida en los apuntes que Lázaro DíaZ DEL VALLE dejó manuscritos en 1658 (“Epílogo y nomenclatura de algunos artífices. Apuntes varios. 1656-1659”, en SÁnCHEZ CANTón, F. J.: Fuentes literarias para la Historia del Arte español, t. II, Madrid, Centro de Estudios Históricos, 1933, p. 391); Thacher adapta las fechas a la documentación que localizó de un "don Francisco de Herrera" (hijo de don Diego de Herrera, boticario de cámara del rey) cuyo enterramiento aparece asentado en el Libro de difuntos de la iglesia parroquial de San Ginés el año 1657, el cual, a pesar de ciertas coincidencias, no debe confundirse con el pintor sevillano; y Martínez Ripoll, para el traslado a Madrid, da por buena la fecha de Ceán (1650), ya que él mismo da a conocer documentación que sitúa al pintor en Sevilla a fines de 1643, incompatible con lo aventurado por Palomino (1640), mientras que para la datación del fallecimiento se hace eco del hallazgo de José LóPEZ NAvío ("Testamento de Francisco Herrera, el Joven", Archivo Hispalense, $\mathrm{n}^{\circ} 110,1961$, p. 274) de un segundo "Francisco de Herrera" entre los asentados en el citado Libro de difuntos de San Ginés, muerto el 29 de septiembre de 1654, y que bien podría tratarse del pintor sevillano.

2 Díaz del VAlle (op. cit., p. 391), en 1658, decía "ser de su mano un descendimiento de la cruz que está en una capilla a la izquierda de S. Felipe el Real, y una estación en el claustro de la Merced calzada de esta Corte"; y CEÁN (op. cit., t. II, p. 279) cita "Dos cuadros en la capilla de S. Miguel" de la Cartuja del Paular.

3 Contrato de Francisco Herrera con la Casa de la Misericordia para la pintura del retablo del Colegio de San Basilio, de 3 de noviembre de 1638, ante el escribano público Mateo de Almonacid (Archivo Histórico Provincial de Sevilla —en adelante AHPS—, Secc. Protocolos Notariales, leg. 17.863, fols. 1068r-1069v); parcialmente trascrito en LóPEZ MARTínEZ, Celestino: Arquitectos, escultores y pintores vecinos de Sevilla, Sevilla, 1928, pp. 66-67. 
Queda claro, según esto, que Herrera el Viejo ya se hallaba en Madrid a principios del mes de julio de 1647. ¿Desde cuándo?: no hay ningún dato que nos lo indique, pero habría que tener en cuenta que el último documento sevillano conocido del pintor está fechado el 24 de diciembre de 16435. Bien es verdad que Ceán afirma que en 1647 pintó cuatro grandes cuadros para el Palacio Arzobispal sevillano, pero ¿hasta qué punto podemos fiarnos de esta fecha cuando están comprobados los notables errores de la cronología que fijó para la biografía del pintor? Recordemos que daba como año aproximado de su nacimiento el de 1576, mientras que la crítica especializada, desde hace ya varias décadas, considera razonablemente que nació hacia el año 1590. Por otra parte, el último cuadro conocido, firmado y fechado por Herrera en Sevilla, es un San José con el Niño realizado para el coro alto del convento de San José de los mercedarios descalzos de Sevilla, hoy en un Museo de Budapest, que tampoco nos saca de dudas: su fecha parece ser un "1645", pero algunos autores leen " 1643 " 6 .

En el poder se comprueba como el pintor deposita toda su confianza en su hermano Juan de Herrera y Aguilar para realizar las gestiones y cobrar lo que le adeudaba la Casa de la Misericordia, algo que nos muestra una normalidad en sus relaciones fraternas que contrasta con la leyenda que corre (desde Palomino) sobre el agrio carácter y la rigidez de condición que lo enfrentó a lo largo de su vida a discípulos y familiares. De Juan de Herrera se conocía su actividad (documentada entre 1627 y 1636) como notable iluminador e inventor de grabados para portadas de libros, aunque no la de cosmógrafo de la Casa de la Contratación que aquí encontramos declarada ${ }^{7}$. Pues bien, Juan de Herrera, en nombre de su hermano Francisco, solicitó el 4 de agosto de 1647 a la Casa de la Misericordia el pago de los 200 ducados que le restaban por cobrar del retablo de San Basilio, adjuntando la carta de poder, una copia del contrato de 1638 y un certificado de conformidad de los monjes basilios (de 15 de junio de 1647) ${ }^{8}$. En el Cabildo extraordinario que celebró la institución sevillana el 11 de agosto siguiente:

se acordó que se comete al señor don Antonio de Çeuallos para que, con la obligaçión que hiço el dicho pintor y con el pareçer de otro ofiçial del mismo arte, bea el retablo y si a cunplido enteramente con la obligaçión que el dicho Francisco de Herrera tiene; y en el primer Cabildo dé quenta dello para que se determine en él lo que conbenga ${ }^{9}$.

No consta si esta comisión se llevó a efecto: ni en las actas, ni en ninguna otra documentación de la Casa de Misericordia. El siguiente documento relativo a este asunto es una nueva carta de poder del pintor Francisco de Herrera, para los mismos fines, fechada en Madrid el 28 de abril de 1648, pero otorgada esta vez a nombre de Joseph Velázquez. ¿Qué pudo suceder para que se paralizara el

\footnotetext{
${ }^{4}$ Poder de Francisco de Herrera a su hermano Juan de Herrera y Aguilar para que reclame los 200 ducados que le restan por cobrar del retablo de San Basilio. Archivo de la Diputación Provincial de Sevilla (en adelante ADPS), Casa Hospital de la Misericordia, leg. 288. Tanto en ésta como en las sucesivas transcripciones de documentos he procurado respetar la grafía del original; sin embargo, para una más fácil lectura, desarrollo las abreviaturas y sigo el uso moderno de la puntuación, acentuación y letras mayúsculas.

5 Martínez Ripoll (op. cit., p. 263) da a conocer, con esta fecha, una carta de arrendamiento de casas otorgada por el pintor a Pablo Rodríguez, procurador de la Real Audiencia de Sevilla (AHPS, secc. P. N., oficio XX, libro $3^{\circ}$ de 1643, ff. 792r-792v).

6 MARTÍNEZ RiPOlL: op. cit., pp. 163-164.

7 Sobre Juan de Herrera y Aguilar, del mismo nombre y apellidos que su padre, véase LAGUNA PAÚL, Teresa: "Juan de Herrera y las reglas de la cofradía de la Vera-Cruz: una contribución al estudio de la miniatura sevillana del siglo XVII", Laboratorio de Arte, $\mathrm{n}^{\circ}$ 8, 1995, pp. 127-156.

8 ADPS, Casa Hospital de la Misericordia, leg. 288.

${ }^{9}$ Libro donde se escriuen los Cabildos y Comisiones que se hazen en esta Cassa de la Misericordia, que se començó desde 20 de septiembre del año de 1643 hasta 19 de abril de 1649. ADPS, Casa Hospital de la Misericordia, libro 16, fol. $261 \mathrm{v}$.
} 
proceso de cobro y hubiese que iniciarlo desde el principio? ¿Acaso enfermó, o murió, Juan de Herrera durante esos meses; o quizás tuvo que partir a algún viaje relacionado con su cargo en la Casa de Contratación? El caso es que existe un segundo documento madrileño, esta vez ante el escribano del rey Antonio Sánchez Tortoles y los testigos Luis Bernardo, Bernabé de la Cruz y, de nuevo, Marcos Serrano, que dice así:

Sépase por esta pública scriptura de poder vieren, como yo, Francisco de Herrera, pintor, bezino de la siudad de Seuilla, residente en esta Corte = Otorgo que doy todo mi poder cumplido, tan bastante como de derecho se requiere y es necessario, a Joseph Belázquez, bezino de la dicha Siudad, espeçial, para que por mí y en mi nombre, y repressentando mi propia persona, pueda pedir y demandar, resiuir, hauer y cobrar, en juiçio y fuera dél, de los hermanos de la Misericordia duçientos ducados en moneda de bellón; los quales se me deuen de resto de la pintura que hise para el altar mayor de Sant Basilio, que a ellos les toca la paga por estar obligados por escriptura ante Matheo de Almonazí, scriuano público de la dicha siudad de Seuilla... [siguen las fórmulas habituales] ${ }^{10}$.

Este Joseph Velázquez era "mercader" y "familiar de número del Santo Oficio de la Inquisición desta çiudad de Seuilla y vecino della en la calle de Francos", según consta en el mandamiento de pago del Padre Mayor de la Casa de la Misericordia y en la carta de pago que otorgó por los 200 ducados en cuestión, cobrados finalmente el día 15 de julio de $1648^{11}$. Nada se sabe de su relación con el pintor: acaso pudiera ser un pariente de su cuñada (mujer de su hermano Jacinto) María Velázquez ${ }^{12}$.

Lo hasta aquí expuesto sigue sin responder a cuestiones tan importantes como son el porqué dejó Francisco de Herrera su taller en Sevilla y se trasladó a Madrid, o cuáles fueron las actividades del pintor en sus años cortesanos. No obstante, el hecho de tener la certeza de que su estancia madrileña duró al menos desde mediados de 1647 hasta las mismas fechas de 1648 (cuando Joseph Velázquez otorga carta de pago en nombre del pintor) y el ser bastante probable que dicha estancia se prolongase definitivamente e, incluso, que hubiese comenzado con algunos meses o, hasta años, de antelación, tiene trascendencia porque modifica en parte lo que hasta ahora se creía sobre su obra y biografía.

El cuadro del Museo Lázaro Galdiano, San José y el Niño Jesús, está firmado y fechado por Herrera en el año 1648 y su pertenencia a la etapa madrileña del pintor queda ya fuera de toda duda $^{13}$. Otro tanto se puede decir de los dos grabados de tarjas ornamentales que conserva el Metropolitan Museum of Art, de Nueva York: una de ellas firmada y fechada en 164914. Y lo mismo de los dos cuadros dados a conocer por Pérez Sánchez y Navarrete, ambos firmados y fechados en 1650: un San Jerónimo, de colección particular, y una Adoración de los Reyes, en el Seminario Diocesano de Vitoria ${ }^{15}$. Si hasta el momento la etapa madrileña del pintor estaba huérfana de obras atribuibles con seguridad, a partir de ahora habrá que tener como tales al menos a éstas, cuya fecha es posterior a 1647.

En cuanto a datos biográficos que es necesario reconsiderar, destaca el hecho de que Herrera el Viejo estuviera en Madrid cuando su hijo, el pintor Francisco Herrera el Mozo, contrajo

10 ADPS, Casa Hospital de la Misericordia, leg. 288.

11 ADPS, Casa Hospital de la Misericordia, leg. 288.

12 MARTínez Ripoll: op. cit, p. 16.

13 Considerada como pintura de su etapa madrileña por aquellos que situaban la llegada a la corte del artista en 1640 y como sevillana por los seguidores de la de 1650. Véase MARTínez RiPOLL, op. cit., p. 167.

14 Martínez Ripoll: op. cit, p. 248.

15 PÉrez SÁnchez, Alfonso E. y NAVArRete Prieto, Benito: “Sobre Herrera el Viejo", Archivo Español de Arte, no 276 (1996), pp. 378-381. 
matrimonio en Sevilla el 9 de septiembre de 1647 con Juana de Auriolis, de la que se separaría a los pocos meses ${ }^{16}$. El hijo se casó en ausencia paterna —no sabemos si también sin su consentimiento-; tras la disolución matrimonial dejó Sevilla por Roma (así se supone desde Palomino) y, probablemente, no volvería a coincidir con su progenitor hasta el periodo de su primera estancia madrileña y últimos meses de vida de su padre: Herrera el Mozo contrató (el 17 de julio) y finalizó (el 28 de octubre) del año 1654 las pinturas del retablo mayor de la iglesia madrileña de San Hermenegildo, del convento de los Carmelitas Descalzos; el día 29 de diciembre de ese mismo año (según López Navío) moría y era enterrado Herrera el Viejo en la parroquial de San Gines ${ }^{17}$

Esta nueva documentación también modifica lo que hasta hoy se venía creyendo sobre la realización del retablo de San Basilio. La localización y publicación de la carta de obligación de Herrera el Viejo con la Casa de la Misericordia y el Colegio de los basilios sevillanos (a falta de otros documentos que indicaran lo contrario) hizo suponer que los términos recogidos en dicho contrato se cumplieron por ambas partes sin problemas: pero, como ya sabemos, no fue así.

La historia de este retablo nace del deseo del patrono del Colegio de San Basilio: un rico mercader de origen griego (nacido en la isla de Citerea) llamado Nicolao Griego Triarchi, que hizo su fortuna en tierras del Virreinato del Perú, singularmente en Valdivia (la ciudad chilena de las minas de oro) y que terminó instalado en Sevilla, donde murió el 23 de diciembre de $1598^{18}$. Antes, el 20 de abril de 1594, había dictado su testamento donde, además de dejar ciertas cantidades para la construcción de la iglesia y de su sepultura en la capilla mayor, dejó una manda que obligaba a sus albaceas y herederos (la institución benéfica y religiosa sevillana conocida como la Casa de la Misericordia) a gastar mil ducados en la realización de un retablo para la capilla mayor de la iglesia del Colegio de San Basilio "como y en la manera que les pareciere" 19 . A partir de este momento y hasta que el retablo fue terminado en 1738 — cuando se acabó de dorar- fueron muchas las vicisitudes que sufrió. En primer lugar, hubo de esperar a que se construyese la iglesia del Colegio, cuya financiación se prolongó hasta 1630; luego, que se levantase en la capilla mayor el sepulcro de piedra con el bulto del difunto; $y$, por fin (el 16 de julio de 1635), fue contratada su ejecución con el ensamblador Fernando de los Ríos por la cantidad de 700 ducados $^{20}$. El día 24 de noviembre de

\footnotetext{
16 MARTínez Ripoll: op. cit, p. 263.

17 Caturla, María Luisa: "La verdadera fecha del retablo madrileño de San Hermenegildo", en Actas del XXIII Congreso Internacional de Historia del Arte (1973), III, Granada, 1978, pp. 49-55; y LóPEZ NAVío, op. cit., p. 274.

18 ADPS, Casa Hospital de la Misericordia, leg. 69: Concierto entre Nicolao Griego y los basilios de Sevilla (7,8 y 9 de enero de 1593); y leg. 33: Jorge de Rodas: testamento que en su nombre otorgó Nicolao Griego (13 de septiembre de 1566).

${ }^{19}$ Testamento de Nicolao Griego ante el escribano público Diego de Almonacir. Sevilla, 20 de Abril de 1594 y Codicilo al testamento de Nicolao Griego ante el escribano público Pedro de Almonacir. Sevilla, 23 de Septiembre de 1596 (ADPS, Casa Hospital de la Misericordia, leg. 33).

20 Remate y concertación del retablo mayor del Colegio de San Basilio entre Fernando de los Ríos y la Casa de la Misericordia, 16 de julio de 1635 (ADPS, Casa Hospital de la Misericordia, leg. 69); este documento es traslado de la escritura pública conservada en el AHPS (Secc. P. N., leg. 490, ff. 598r-609v) que en su día fue transcrita y publicada parcialmente por Celestino LóPEZ MARTínEZ (op. cit.: pp. 163-165), el cual, aplicando su particular criterio de entresacar tan sólo los datos que consideraba esenciales de los farragosos documentos notariales, se dejó en el tintero algunos tan importantes como las medidas detalladas de las partes que componían el retablo, que aquí transcribo: "Es condición, que a de hacer la persona en quien se rematare el dicho retablo, dos escudos de talla de madera de borne o cedro, donde se an de poner las armas de Nicolao Griego; en los quales a de aver unos óbalos donde se pinten las dichas armas, que tengan dos baras de alto y bara y media de ancho, a contento y satisfacçión de los dichos Padre Abad y diputados, y para más claridad de la obra se le espresan por menor las medidas de los quadros mayores y menores y sagrario, conforme a la montea y traça que está elegida por nos, los dichos Abad y monges y diputados, y de todo el dicho retablo, que son como se siguen: el retablo a de tener, conforme a la dicha montea y demostraçión del pitipié: desde el suelo hasta el último remate, diez y seis baras menos una terçia, de alto; e de ancho, ocho baras menos dos dedos = las columnas an de ser
} 
1637, casi dos años y cinco meses después — que no los ocho meses que fijaba el contrato—, quedaba instalada la carpintería del retablo en su lugar de destino ${ }^{21}$.

El paso siguiente fue la contratación de las pinturas del retablo. Un año después de la colocación de la obra de ensamblaje, el día 3 de noviembre de 1638, la Casa de la Misericordia, el Colegio de San Basilio y el pintor Francisco de Herrera, conocido como el Viejo, firmaban una carta de obligación por la cual este último se comprometía a realizar un total de diez y ocho pinturas, por un precio de 300 ducados, cantidad que restaba de la asignación de Nicolao Griego para el altar mayor de la iglesia de San Basilio. Tal y como era habitual en aquella época, el pintor recibió un tercio (cien ducados) de la cantidad total en el mismo momento de la firma del contrato, dejando el cobro del segundo tercio "para luego que aya acauado el primer lienzo principal del dicho quadro", y los cien ducados restantes para cuando estuviera "acauado de todo la dicha pintura y puesta en el dicho quadro"; cosa que se comprometió a cumplir para el día 15 de junio de 1639, es decir, ocho meses y doce días después de firmado el documento. Las pinturas del retablo de San Basilio se han venido datando de acuerdo a estos datos: entre la fecha de la firma (noviembre de 1638) y la fecha prevista para su entrega (junio de 1639). Sin embargo, a partir de ahora será necesario revisar este criterio porque, como ya sabemos, en este caso la realidad de los hechos no se ciñó a lo previsto en el documento notarial. Los documentos del archivo de la Casa Hospital de la Misericordia muestran como Francisco de Herrera el Viejo (a través de Joseph Velázquez) no llegó a cobrar los doscientos ducados correspondientes a los dos últimos tercios de su paga hasta el lejano día de 15 de julio de 1648: nueve años y un mes después de lo previsto en el contrato. Pero, aún antes del hallazgo de estos documentos, existían algunos indicios de este problema en la citada escritura de obligación conservada en el AHPS, transcrita (también parcialmente) por López Martínez: llaman la atención tres anotaciones del escribano en el margen izquierdo de la cabecera del documento, correspondientes a otros tantos traslados del mismo realizados en distintas fechas ${ }^{22}$. No es algo muy habitual en este tipo de contratos y cuando aparecen suelen ser indicio de pleitos o reclamaciones. La tercera de estas anotaciones registra la copia sacada el día 24 de mayo de 1647, copia que conocemos porque se encuentra entre la documentación hallada en los papeles de la Casa de la Misericordia que fue presentada por Juan de Herrera al Cabildo de la misma acompañando a la solicitud del pago de los 200 ducados que se debían a Francisco de Herrera. Las otras dos son de fecha mucho más temprana: la primera de 3 de marzo de 1639 y la segunda de 30 de abril del mismo año. Aunque en las anota-

\footnotetext{
estriadas en buelta, y los capiteles corintio de ojas haupadas como lo demuestra la pintura y montea $=$ el quadro mayor y prinçipal del dicho retablo a de tener la moldura de grueço una terçia menos dos dedos, y de ancho, una quarta y tres dedos $=$ los pequeños quadros tienen, de grueso, una quarta menos dos dedos $=$ el banco tiene dos terçias de grueço, sin los buelos = las columnas, tienen de grueso media bara menos seis dedos de diámetro = el sagrario tiene una vara de grueço = las columnas del sagrario del primer cuerpo tienen de alto una bara, han de ser estriadas en buelta, una ochava de grueço la caña de ellas = el primer cuerpo del sagrario tiene dos baras menos terçias de alto $=$ y el segundo cuerpo, tiene, desde la cornixa principal hasta lo más alto de la cornixa última, bara y terçia = la media naranja tiene de alto media bara $=$ el remate tiene bara, de alto = la cruz, tiene una terçia y dos dedos. El gueco del cuadro principal, tiene de alto siete baras y de ancho tres y media $=$ el de encima, tiene de ancho tres baras menos terçia y de alto tres menos quarta $=$ el del remate alto, bara de alto y bara y quarta de ancho $=$ los de las entrecalles, el primero alto tiene dos baras de alto y una de ancho, y todos los demás como ban baxando, han de tener bara y media de alto y un bara de ancho $=\operatorname{los}$ que an de estar al pie del altar an de tener, de guecos, de alto una bara menos dos dedos y de ancho dos tercias = el sagrario a de tener de alto quatro baras y terçia con el remate y en ancho dos baras y terçia, y dos dedos = el plano del banco al pie, queda una çitanica donde se an de poner unos letreros."

21 ADPS, Casa Hospital de la Misericordia, leg. 69.

$22 \mathrm{He}$ aquí las anotaciones (fol. 1068r): "Di testimonio en papel del quarto sello en Sevilla, tres de março de mill y seiscientos y treinta y nueve años, de que doy fee [rúbrica de Mateo de Almonacid]"; "Di traslado, el primero pliego del sello segundo y lo demás papel común, en Sevilla. a treinta de abril de mill y seiscientos y treinta y nueve años, de que doi fee [rúbrica de Mateo de Almonacid]"; "Di otro traslado en papel del sello segundo e con..., en veinte y quatro de mayo de mill y seiscientos y quarenta y siete, de que diy fee [rúbrica de Mateo de Almonacid]".
} 
ciones no se especifica para quién o quiénes se realizaron los traslados del documento, es muy posible que los tres fueran solicitados a instancias del propio Herrera: el pintor, una vez que hubo terminado el cuadro principal y ante la falta de pago del correspondiente segundo tercio por parte de la Casa de la Misericordia (tal como se fijaba por contrato) debió plantearse el inicio de algún tipo de reclamación basada en lo estipulado en el contrato: de ahí los sucesivos traslados que pidió al escribano $^{23}$. Así, la primera copia está fechada a los cuatro meses exactos de la firma del original: tiempo suficiente para haber pintado el gran lienzo y comprobar que no se cumplía con su segunda paga; el siguiente traslado se realizó apenas dos meses después. Puede ser que ambas copias fueran adjuntadas a sendas reclamaciones: una, ante la Casa de la Misericordia como pagadora y, otra, ante el Colegio de San Basilio, fiador con sus "bienes y rentas abidos y por hauer". En cualquier caso no hay ningún indicio de que el conflicto llegase al ámbito de los tribunales.

Las causas del dilatado impago radicaban en la falta de liquidez que sufría la dotación de Nicolao Griego administrada por la Casa de la Misericordia, su heredera. Las rentas dejadas por el mercader griego provenían de diversos tributos que tenían que pagar anualmente, en su parte principal, el conde de Cantillana y el duque de Alcalá. Cuando estos pagos no se hacían efectivos, algo frecuente en el caso del conde de Cantillana, la dotación no podía hacer frente a sus obligaciones. Estos problemas en los pagos, que ya habían dilatado ampliamente los plazos de construcción de la iglesia, el sepulcro y el retablo, afectaron de lleno a las pinturas contratadas por Francisco de Herrera ${ }^{24}$. La situación se hizo tan crítica que, además de no hacer posible el pago del segundo y tercer plazos de las pinturas de Herrera el Viejo, hizo que la Casa de la Misericordia suspendiese en 1640 las honras que anualmente se celebraban en el Colegio de San Basilio en memoria de su fundador y en cumplimiento de una de sus mandas testamentarias: no había dinero ni para el "aceyte, y vino y sera" necesarios para su realización ${ }^{25}$. La "baja de la moneda" del 15 de septiembre de 1642 obligó a la Casa de la Misericordia a emplear el dinero de las dotaciones que administraba en un juro para así evitar mayores pérdidas, pero esto dejó sin liquidez buena parte de sus fondos. Esta baja también afectó a otros tributarios de la institución que se vieron en dificultades para cumplir con sus obligaciones de $\mathrm{pago}^{26}$. Hubo

${ }^{23} \mathrm{La}$ escritura recoge la posibilidad de interponer pleito por parte del pintor si no se le pagasen los plazos correspondientes: “...por razón de lo qual ha de ser obligada la dicha Cassa de la Missericordia de me dar e pagar los dichos trescientos ducados que anssí restan cumplimiento a los dichos vn mill ducados de la dicha manda, en esta manera: los cien ducados dellos que de pressente se me han de dar; y los otros cien ducados luego que aya acauado el primer lienzo principal del dicho quadro; y los otros cien ducados restantes, luego que de todo punto esté acauado de toda la dicha pintura, y puesta en el dicho quadro. Y para ello, a cada plazo y paga, e de poder executar a la dicha Cassa y a sus bienes y rentas en birtud desta escriptura y mi juramento o de quien mi caussa hubiere, sin otra prueba, de que quedo relebado..."

${ }^{24}$ En un informe de la Contaduría de la Casa de la Misericordia, fechado el 31 de marzo de 1666, se explica con detalle el origen, evolución e importe de las rentas dejadas por Nicolao Griego para que se cumplieran las obligaciones de su dotación (ADPS, Casa Hospital de la Misericordia, leg. 69). En la sesión celebrada el 8 de febrero de 1637 por el Cabildo de la Casa de la Misericordia, se leía una carta de don Juan Vicentelo de Leca, conde de Cantillana — quién, por cierto, también era hermano de la propia Casa- en la que éste pretendía que se justificase su ausencia a las reuniones de dicho Cabildo por su actual situación de desterrado, y anteriormente ingresado en prisión, y que se le pagasen sus correspondientes dietas como si asistiera a las mismas; además, pedía que no se le pusiese pleito por el dinero que debía a la dicha Casa porque su intención era pagarlo en el próximo mes de abril (ADPS, Casa Hospital de la Misericordia, lib. 14). El Cabildo de $1^{\circ}$ de marzo siguiente autorizaba al Procurador del Colegio de San Basilio a hacer directamente las diligencias necesarias para obligar a pagar al conde, algo que se repitió en otras ocasiones y que tenía antecedentes en fechas tan tempranas como la de 1605 (Cabildo de 1 de marzo de 1637, Comisión de 24 de enero de 1641 y Cabildo de 5 de febrero de 1645, ADPS, Casa Hospital de la Misericordia, libs. 14, 15 y 16 respectivamente).

25 Aunque poco después rectificara su decisión adelantando de su propia "arca" y "por esta vez" el dinero que era menester; solución provisional que se repitió al menos en otra ocasión (Cabildo de 2 de diciembre de 1640, Comisión de 24 de enero de 1641 y Comisión de 27 de enero de 1642, ADPS, Casa Hospital de la Misericordia, lib. 15).

26 Comisión de 4 de agosto de 1646 (ADPS, Casa Hospital de la Misericordia, lib. 16) y Cabildo de 22 de marzo de 1643, donde se presentó una petición de los duques de Medina Sidonia y de Alcalá respecto a un pleito pendiente "causado por la baja de la moneda" (Ídem, lib. 15) 
un acuerdo con el conde de Cantillana en 1644, que no dio resultados, antes de que, por fin, la Casa de la Misericordia cobrase 6.000 reales de uno de los fiadores de dicho conde; esto sucedía en septiembre de $1645^{27}$. A partir de este momento los monjes basilios reclamaron a la Casa de la Misericordia el pago de las cantidades atrasadas de una manda de 500 ducados anuales que el Griego dejó para su sustento. Después de una serie de reclamaciones por parte del Colegio y de reuniones de la Comisión de Hacienda y del Cabildo de la Casa de la Misericordia, y tras otro acuerdo con el conde de Cantillana, se resolvió en la Comisión de 23 de diciembre de 1647 pagar al Colegio de San Basilio un total de 75.915 mrs correspondientes a las cuentas de 1646 y de lo corrido en 164728 .

Fue precisamente en 1647 cuando Francisco de Herrera —o, si ya estaba en Madrid, la persona que velara por sus intereses_-, informado de que, al fin, volvía a haber dinero en la dotación de Nicolao Griego, se movilizó para insistir en la reclamación de los 200 ducados que se le adeudaban. El primer paso dado fue la solicitud, una vez más, de la copia del contrato, que, como se vio, fue emitida el 24 de mayo de dicho año. Tres semanas después, el Abad y los padres consiliarios del Colegio de San Basilio certificaban por escrito, en el reverso de la última hoja del propio traslado de la escritura, que Francisco de Herrera había cumplido con lo estipulado en la misma "a toda perfeción y satisfación, sin que para su cumplimiento falte cosa alguna" 29 . Ya sólo faltaba presentar, junto a esta documentación, la petición formal a la Casa de la Misericordia de que se abonaran los 200 ducados. Pero Francisco de Herrera no pudo hacerlo personalmente porque se encontraba en Madrid. El resto de la historia de la liquidación de la deuda ya la conocemos.

Estos hechos obligan a reconsiderar la cronología de las propias pinturas del retablo, hasta aquí consideradas todas ellas de entre octubre de 1638 y junio de 1639: a partir de ahora habrá que ampliar su arco cronológico hasta la fecha de 15 de junio de 1647, en que los frailes emitieron el primer certificado del Colegio de San Basilio diciendo que las pinturas estaban hechas y colocadas en su retablo. Sin embargo, en lo que respecta al cuadro principal, en el Museo de Bellas Artes de Sevilla, conocido como La visión de San Basilio (aunque su título correcto debe ser La Misa de San Basilio, pues representa el momento en que Cristo y sus Apóstoles le hacen entrega de ese tradicional texto litúrgico), es bastante probable que, según lo estipulado, Francisco de Herrera lo comenzase inmediatamente para, una vez terminado, poder cobrar el segundo tercio de su paga, tal y como se exigía en el contrato ${ }^{30}$. Éste puede haber sido un momento crítico: cuando, una vez finalizado el cuadro principal, Herrera comprobó que la Casa de la Misericordia no le pagaba la parte acordada y, en consecuencia, comenzó los trámites para su reclamación (copias del contrato de 3 de marzo y 30 de abril de 1639). Nada se sabe de lo que pudo ocurrir a partir de este momento: si el pintor continuó trabajando en el resto de las pinturas durante el año 1639 es algo que no se puede afirmar ni descartar. La única conclusión que se deduce a partir de los datos disponibles es que las pinturas pudieron realizarse en cualquier momento entre 1638 y 1647 . Este nuevo marco cronológico y el hecho de que Herrera parece que ya estaba en Madrid cuando llegó el momento de instalar los cuadros en el retablo - porque no parece creíble que el pintor lo hubiese hecho antes de tener asegurado el pago de su trabajo - refuerza algunas dudas en relación con la

27 Comisiones del 5, 17 y 29 de octubre y Cabildo de 13 de noviembre de 1644; Comisión de 18 de septiembre de 1645 (ADPS, Casa Hospital de la Misericordia, lib. 16).

28 Cabildo de $1^{\circ}$ de julio de 1646 , Comisiones de 10 de abril y de 23 de diciembre de 1647 (ADPS, Casa Hospital de la Misericordia, lib. 16).

29 (ADPS, Casa Hospital de la Misericordia, leg. 69).

30 Herrera realizó "un borrón" del cuadro principal, probablemente para presentarlo a los comitentes del retablo, los basilios y/o la Casa de la Misericordia. Dicho borrador estaba, hacia 1780, en manos del ilustrado Conde del Águila (Fernando de Espinosa Maldonado de Saavedra), historiador, bibliófilo y coleccionista de pinturas y grabados, que muy probablemente se hizo con él debido a su condición de Padre Mayor de la Casa de la Misericordia (CARRIAZO, Juan de Mata: "Correspondencia de don Antonio Ponz con el Conde del Águila”, Archivo Español de Arte y Arqueología, V, 14, 1929, p. 169). 
autoría de algunas pinturas, que por algunos ya se habían venido considerando como obras de taller o copias de Herrera ${ }^{31}$. Una de las posibilidades a considerar es la de la participación de Francisco Herrera el Mozo, formado en el taller paterno y que, por lo tanto, bien pudo colaborar en la realización de estos cuadros. Si al contratar el retablo en el año 1638, el futuro pintor tenía tan sólo once años, la edad de muchos aprendices, en 1647 (mismo año de su boda) ya tenía veinte, edad de muchos oficiales e incluso maestros del arte de la pintura. Otra posibilidad, compatible con la anterior, es que Juan de Herrera, el hermano del pintor, que realizó las gestiones finales para el cobro y, posiblemente, para la instalación de las pinturas en su retablo, él mismo buen dibujante e iluminador, ayudase a completar alguna parte de los cuadros ante la ausencia de su hermano Francisco y así poder instalar en el retablo la totalidad de las pinturas y hacer posible su cobro. Las tres semanas transcurridas entre la fecha del tercer traslado del contrato y la del certificado basilio pudieron ser el tiempo necesario para rematar y colocar todas las pinturas en su destino. Otra cuestión, que también habrá de ser revisada, es la que afecta al numeroso grupo de obras que la crítica ha venido datando, con mayor o menor precisión, basándose en su comparación con las pinturas del retablo de San Basilio, ahora fechables entre 1638 y 1647.

A lo largo de su historia, el retablo mayor de la iglesia de San Basilio de Sevilla se vio amenazado repetidamente y sufrió las graves consecuencias de una serie de importantes acontecimientos: la invasión francesa, la desamortización y extinción de la orden de los basilios, la revolución "Gloriosa" y, en las últimas décadas, como veremos, la fiebre de la "restauración" arquitectónica ${ }^{32}$. Y no sin consecuencias para su integridad: de las diez y ocho pinturas recogidas en el contrato, actualmente se conservan nueve en el Museo de Bellas Artes de Sevilla: el cuadro principal (La Misa de San Basilio) y ocho retratos de los hermanos del santo - otros dos, que faltan para completar los diez que dice el contrato, desaparecieron del Museo entre 1840 y 1845-; el lienzo que se situaba en el centro del segundo cuerpo (Los fundadores de las órdenes monásticas tomando su regla de San Basilio), que formó parte de la colección del mariscal Soult, terminó el Museo del Louvre; y, hasta ahora, no se sabía de la existencia de ningún fragmento del retablo y faltaban por localizar los seis retratos que, situados en la predela del retablo, representaban a los padres y abuelos del santo titular. Aquí quiero comunicar la localización de una parte de la máquina del retablo y de tres de sus pinturas realizadas por Francisco Herrera el Viejo: los retratos de sus padres y la puerta del sagrario con un Niño Jesús.

Veamos los antecedentes: en septiembre de 1835 había sido clausurado el Colegio de San Basilio de Sevilla y suprimida la orden basilia. La recién creada Comisión de Monumentos recogió las pinturas del retablo que habían de pasar al nuevo Museo Provincial, como se dice en el acta de su sesión de 11 de abril de 1836:

Se dio cuenta por el Sr. Marqués [de Arcohermoso] de haberse recogido del Convento de San Basilio los cuadros que había en dicho edificio; igualmente se presentó la lista de los que habían quedado para el

\footnotetext{
31 Según John S. THACHER (“The Paintings of Francisco de Herrera, the Elder”, The Art Bulletin, vol. XIX, n’ 3, sept. 1937, pp. 326-380) los lienzos que representan a los hermanos y a un familiar de San Basilio (Mº de Bellas Artes de Sevilla) estarían pintados por algún miembro del taller de Herrera siguiendo dibujos de éste. Seis de estas pinturas estaban consideradas en el Inventario de los cuadros llevados por los franceses al Alcázar de Sevilla como "Copias de varios autores" (GómEz IMAZ, Manuel: Inventario de los cuadros sustraídos por el Gobierno Intruso en Sevilla (1810), $2^{\circ}$ ed., Sevilla, 1917, p. 155)

32 En la ponencia "Las tribulaciones del retablo mayor del Colegio de San Basilio, de Sevilla, pintado por Francisco Herrera el Viejo", que presenté en el Encuentro La conservación de retablos. Catalogación, Restauración y Difusión (Universidad de Cádiz, 12-14 de abril de 2005, El Puerto de Santa María) se trató pormenorizadamente de la historia del retablo.
} 
adorno del templo firmada por los Capellanes, y la Junta acordó se archivase la nota en Secretaría y que para el reemplazo de los recogidos se sacasen del almacén del Museo los necesarios al efecto, anotándose y firmándose por los referidos Capellanes... 33

De este modo, los cuadros de Herrera fueron sustituidos por otros: porque se había resuelto que la iglesia del desaparecido colegio debía de permanecer abierta al culto. Y así, su retablo mayor - ya sin lienzos originales, ni monjes — vivió los que serían sus últimos años, puesto que la llegada de la revolución de septiembre de 1868, "la Gloriosa", supuso su golpe de gracia ${ }^{34}$. Clausurada la iglesia por la Junta Revolucionaria de Sevilla, el Ayuntamiento acordó que se hicieran inventarios de todos los enseres existentes en el interior de los edificios suprimidos y se trasladasen al Museo las pinturas y otras obras de arte, mientras que las imágenes y objetos de culto fueran entregadas al Arzobispado sevillano para que dispusiera de ellas como tuviese a bien. En aplicación de lo acordado, el día 4 de noviembre se presentó en la iglesia de San Basilio D. Julián de Flores, Regidor comisionado por el Ayuntamiento, acompañado de un secretario, y en presencia del sacristán del templo realizaron el correspondiente inventario, gracias al cual hoy podemos conocer cual era entonces la situación del altar mayor y su retablo:

\author{
Altar Mayor \\ Un San Basilio con dos Santos \\ Seis cuadros en el altar \\ Seis id. encima de estos, de lienzo... ${ }^{35}$
}

Nos interesan especialmente, de entre todo lo apuntado, esos "Seis cuadros en el altar" ya que, puestos en relación con los otros "Seis id. encima de estos, de lienzo", indican que el autor del inventario nos está dando a entender: primero, que dichas pinturas no eran sobre lienzo y, por tanto, lo más probable es que fuesen sobre tabla y, segundo, que se encontraban en la parte inferior del retablo, debajo de los seis lienzos, y "en el altar", entendido en este caso como ara y banco del retablo. Si además tenemos en cuenta que seis eran también las pinturas que representaban a los padres y cuatro abuelos de San Basilio que se le pidieron a Francisco de Herrera para el banco del retablo, parece evidente que se trata de las mismas pinturas. Obras que por su pequeño tamaño y por la mayor dificultad que suponía su desprendimiento del retablo permanecieron fijadas a él hasta ese momento ${ }^{36}$. Sin embargo, nada se dice en el inventario de la pintura de Dios Padre en el ático del retablo, seguramente también sobre madera (quizás un relieve), ya que en el contrato se indica que se había de pintar sobre una "tarjeta"37. Tan sólo hay noticias de uno de los lienzos

33 Libro Primero de Actas de la Comisión de Monumentos de Sevilla (1835-1853) (Archivo de la Real Academia de Bellas Artes de Santa Isabel de Hungría)

34 El primero en tratar de los efectos de la revolución septembrina en el patrimonio histórico-artístico sevillano fue TAssara y GonzÁlez, José María: Apuntes para la historia de la revolución de septiembre de 1868, Sevilla, 1919. María Luisa Fraga IRIBARNE hizo una introducción a este momento histórico muy bien documentada en su libro Conventos femeninos desaparecidos. Arquitectura religiosa perdida durante el siglo XIX en Sevilla (Sevilla, 1993).

35 Archivo Histórico Municipal de Sevilla —en adelante AHMS_, Colección Alfabética (voz Conventos y Exconventos), caja 271

36 Los retratos de los padres y abuelos de San Basilio no pueden ser los seis lienzos que en 1810 se inventariaron en la sala XVII, $\mathrm{n}^{\circ}$ 371, del Alcázar sevillano, como supone MARTínEZ RIPOLL (op. cit., p. 194) al dar una altura de 1/2 vara a estos cuadros, cuando, en realidad, Gómez IMAZ dice que tenían 1 vara y 1/2 (op. cit., p. 155); medida que sí se corresponde con las de los lienzos de las calles laterales, en el museo sevillano, y con las del citado contrato de Fernando de los Ríos.

37 LÓPEZ Martínez: Arquitectos..., p. 67. 
que sustituían a los del retablo original: era "Un cuadro sobre el altar mayor que representa una Virgen que no parece de mérito, y su tamaño como de dos varas"38. El apunte de "Un San Basilio con dos Santos" se refiere a esculturas de vestir, en madera ${ }^{39}$.

El retablo, desmontado, quedó en los almacenes del Arzobispado junto a otros muchos enseres que eran solicitados por las parroquias del mismo para cubrir sus necesidades. Esta fue el motivo de que nuestro ya despiezado retablo fuese destinado a la iglesia parroquial de Santa María de la Oliva, en Salteras ${ }^{40}$.

D. Manuel Vejarano y Cerón, cura párroco de este pueblo sevillano, se interesó desde los primeros momentos de este agitado momento histórico por conseguir algún beneficio para su parroquia. El 10 de noviembre de 1870, D. Manuel firmó dos recibos a D. Francisco Florén, el encargado por el Arzobispado de estos asuntos, uno por "un cancel de tablas lisas sin postigos y bien traído, procedente de la Yglesia de San Basilio" y, el otro, por "un retablo de talla dorado, bastante deteriorado y falto de piezas, que servía de altar mayor en la Yglesia de San Basilio"41. El retablo llegó sin su correspondiente ara ya que, el mismo día 10, el párroco, entre otras cosas, pedía "una ara además, para el altar que se me concedió de la Yglesia de San Basilio, y que trato de poner al instante" 42 .

La iglesia de Santa María de la Oliva, en Salteras, fue restaurada en 1971 bajo la dirección del arquitecto Rafael Manzano y, según cuentan los saltereños, como resultado de este proceso, se "eliminaron" diversos elementos de su mobiliario; caso del cancel — antiguo de la iglesia de San Basilio- y de algún que otro retablo, entre ellos uno grande y con guirnaldas de frutas talladas, de la Virgen de la Soledad. Es muy probable que éste fuese el primitivo retablo basilio, puesto que ningún otro de los hoy existentes se corresponden, por tamaño y por estilística, con el mismo ${ }^{43}$.

No obstante, un pequeño retablito situado en una capilla de la nave de la epístola (fig. 1) sí que poseía algunos rasgos formales coincidentes con el estilo de los retablos sevillanos del primer tercio del siglo XVII y, sobre todo, con algunos detalles similares a los descritos en el contrato que Fernando de los Ríos firmó con los monjes basilios. El estudio detallado de este retablo y su cotejo con los datos que aparecen en los contratos del ensamblaje, pintura y dorado del retablo del Colegio San Basilio, pero, sobre todo, los rasgos estilísticos y la iconografía de las pinturas que se conservan en su banco (un Niño Jesús en la puerta del sagrario y sendos anciana y anciano a sus lados) confirman que, efectivamente, el actual retablito reutiliza partes de la gran máquina basilia, incluidas las tres pinturas sobre tabla que considero que fueron pintadas por la mano de Francisco Herrera el Viejo.

38 Acta de incautación por la Administración de Hacienda Pública de la iglesia de San Basilio, 27 de noviembre de 1868, AHMS, Colección Alfabética (voz Conventos y Exconventos), caja 271.

39 Las tres imágenes aparecen en varios documentos de entrega y recibos del Ayuntamiento y del Arzobispado (AHMS, ya citado y Archivo General del Arzobispado de Sevilla — en adelante AGAS—, Secc. II, Asuntos Despachados, legs. 314 y 315 ).

40 Este dato ya fue dado a conocer por José María TASSARA (op. cit., p. 102) en el apartado que dedica a la iglesia de San Basilio, sin que desde entonces haya sido tomado en consideración por los investigadores que han estudiado las pinturas de Herrera el Viejo.

41 AGAS, Secc. II, Asuntos Despachados, leg. 315.

42 AGAS, Secc. II, Asuntos Despachados, leg. 314.

43 Agradezco a don José María Gómez Martín, párroco de la iglesia de Santa María de la Oliva de Salteras, las atenciones y facilidades dadas para el estudio del retablo. En el Archivo Central de Ministerio de Cultura (Caja 71.134) se conserva la memoria de restauración de la iglesia parroquial de Salteras, por el arquitecto Rafael Manzano Martos (1971). Según ésta, el objetivo de las obras era el "zunchado de arquerías de separación de naves y realces de las cimentaciones" (Fuentes documentales para el estudio de la Restauración de Monumentos en España, Madrid, $\mathrm{M}^{\circ}$. de Cultura, 1989, p. 132). 
Figura 1. Actual altar del Sagrado Corazón, iglesia de Santa María de la Oliva, Salteras.

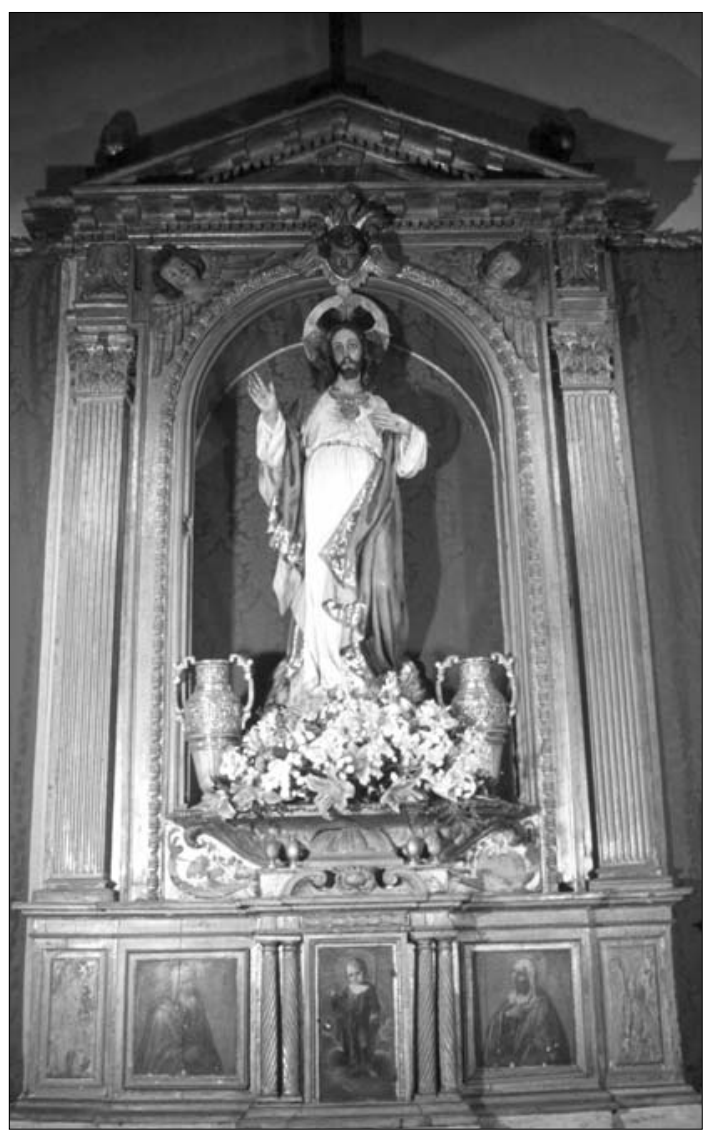

Su configuración es la de un retablo de hornacina entre pilastras corintias acanaladas y rematada por un frontón recto; el banco lo conforman un sagrario entre pares de columnas torsas de orden dórico, rematado por un frontón curvo partido y cúpula gallonada de base cuadrada, que está flanqueado por sendas tablas pintadas.

Las medidas de la arquitectura que enmarca la actual hornacina coinciden con la que albergó en su origen a alguno de los dos cuadros rematados en medio punto que se guardan en el Museo de Bellas Artes de Sevilla y que representan a los dos obispos hermanos de San Basilio: San Gregorio Niseno y San Pedro de Sebaste. En el contrato con el ensamblador Fernando de los Ríos se especifica que el "hueco" ocupado por estos cuadros ("primero alto" de las dos "entrecalles") había de medir dos varas de altura, a las que sumando un cuarto de vara menos dos dedos de grueso de la moldura, tanto por arriba como por abajo, daría un total de dos varas y media menos cuatro dedos de ancho, que en centímetros vienen a ser unos 204; y de ancho una vara, que con sus molduras correspondientes a ambos lados serían otros $120 \mathrm{~cm}^{44}$. Pues bien, las medidas del hueco de la hornacina, sin tener en cuenta un estrecho marco añadido muy posteriormente para sujetar un cristal, son casi las mismas: 203 x $122 \mathrm{~cm}$. Esta estructura lignaria, y su correspondiente simétrica, eran las que estaban situadas en el segundo cuerpo del retablo, albergando los cuadros

\footnotetext{
44 ADPS, Casa Hospital de la Misericordia, leg. 69.
} 


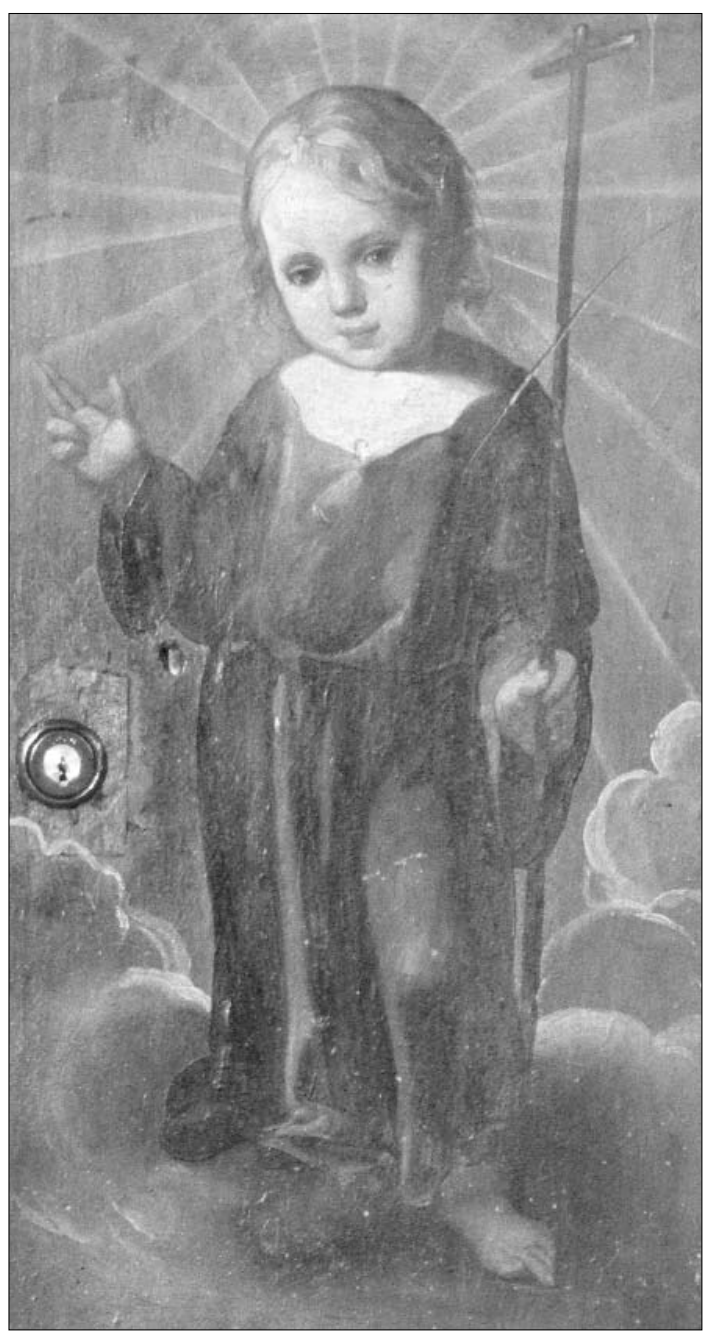

Figura 2. Niño Jesús en la puerta sagrario.

de los citados obispos y flanqueando la pintura de Los fundadores de las órdenes monásticas tomando su regla de San Basilio, hoy en el Museo del Louvre.

La parte inferior del pequeño retablo de Salteras, que hace las funciones de banco, también perteneció al retablo de San Basilio, concretamente al primer cuerpo de su monumental sagrario. La altura de éste, según contrato, debía de ser de cuatro varas y tercia con el remate $(366 \mathrm{~cm}$.) y su ancho, de dos varas y tercia con dos dedos $(200 \mathrm{~cm}$.). El primer cuerpo, de dos varas menos tercia de alto $(140 \mathrm{~cm}$.) con columnas de una vara $(84,5 \mathrm{~cm}$.); mientras que el segundo, de vara y tercia $(112 \mathrm{~cm}$.), estaba rematado por una cúpula semiesférica de media vara de radio $(42 \mathrm{~cm}$.) y una cruz de una tercia y dos dedos $(31,6 \mathrm{~cm}$.). De toda esta imponente arquitectura, hoy sólo queda en la parroquia de Salteras la caja del sagrario y dos pequeñas pinturas a sus lados: conjunto que estaría albergado en el primer cuerpo arquitectónico del sagrario original (sus medidas son: la altura máxima en la cúpula sobre el sagrario, $88 \mathrm{~cm}$; la anchura total, $217 \mathrm{~cm}$ ).

Los pares de columnas torsas que flanquean la puerta del sagrario concuerdan formalmente con las grandes columnas "estriadas en buelta" que, según el contrato con el ensamblador, sus- 
tentaban el primer cuerpo del retablo. El resto de elementos arquitectónicos y decorativos del actual retablo (pilastras, cornisas, frontones, cabezas de ángeles, cartela, remates ovoides) está realizado según los rasgos estilísticos habituales en los altares que se hacían en Sevilla durante las primeras décadas del siglo XVII. La forzada inserción de la cupulita del sagrario en la ménsula que sirve de base a la actual hornacina es consecuencia de la reutilización de partes del retablo pictórico preexistente, adaptadas en su momento para que pudiera albergar una escultura, y testimonio del origen fragmentario de este retablo.

El dorado del retablo de San Basilio fue realizado en dos momentos y, sobre todo, siguiendo dos técnicas y materiales diferentes: oro bruñido en el sagrario y corladura de plata para el resto ${ }^{45}$. Pues bien, en la parte del sagrario y a pesar de una gruesa capa de purpurina que cubre la mayor parte de su superficie, se aprecian zonas en las que el oro bruñido se conserva perfectamente, incluida su decoración incisa a base de líneas cruzadas y estrellas. Esto es claramente apreciable en los planos que se hallan tras las dobles columnas pero, sobre todo en las paredes internas del sagrario, que conservan intactos el brillo y acabado del dorado original. La arquitectura de la hornacina, sin embargo, está en su mayor parte libre de la capa de purpurina, y es posible apreciar un dorado mucho menos intenso y luminoso que el del oro bruñido y con una cierta textura craquelada, fruto del envejecimiento de la mano de corladura que cubre la base de plata.

La puerta del sagrario (que en su faz interior, dorada, dibuja con un ligero relieve una custodia) muestra en la parte exterior de su tabla la pintura - no recogida en el contrato de Herrera- de un Niño Jesús Salvador (44,5 x 22,5 cm.), de pie sobre nubes, bendiciendo con su mano derecha, sujetando una larga vara rematada en cruz con su izquierda y vestido con una túnica marrón oscura, de mangas anchas, ceñida por una correa (fig. 2): estos últimos elementos propios del hábito monacal usado por los basilios. La pintura de la tabla de la parte izquierda (35 x $31,5 \mathrm{~cm}$.) representa de medio cuerpo a un venerable anciano, calvo y de largas barbas blancas, que se apoya sobre un bastón y dirige su mirada hacia lo alto (fig. 3). El halo que rodea su cabeza indica la santidad del personaje. La tabla del lado derecho $(35$ x $31,5 \mathrm{~cm}$.), compuesta de manera similar pero de forma simétrica, figura una mujer madura, vestida con un manto rosáceo y cubierta por un velo blanco, que sujeta un libro con su mano izquierda mientras que

\footnotetext{
45 En el año 1640, Gaspar de Rivas, maestro dorador y pintor, contrató con los basilios por 130 ducados el dorado — con oro bruñido- y el estofado de la porción más importante simbólicamente de su retablo: el sagrario. El contrato fue dado a conocer, también parcialmente, por Celestino LóPEZ MARTíneZ (Retablos y esculturas de traza sevillana, Sevilla, 1928, p. 166) según el documento de 8 de marzo de 1640 conservado en el AHPS, Secc. P. N., leg. 2603, fols. 732v-733v. En este caso, López Martínez omitió las especificaciones técnicas del acuerdo: “...que los aparejos an de ser delgados y no se a de empastar, si no fuere hondura o rotura de clavo, y a de ir estofado en las partes y lisas y lo demás que requiere la obra, a vista y parecer de maestros que dello entiendan y a contento de la comunidad del dicho Colegio, de oro bruñido, según y como lo abemos tratado y concertado, para cuyo efecto tengo en mi poder el dicho sagrario y lo daré acauado en toda perfección dentro de dos meses y medio que corren desde oi..." El dorado del resto del retablo fue contratado el 4 de septiembre de 1738, con Miguel Delgado Moreno, maestro dorador, por 8.500 reales de vellón y el compromiso de tenerlo terminado en el plazo de cuatro meses; pero a diferencia del sagrario, el retablo se recubrió "de plata bañada con corladura de modo que paresca propio oro y que siempre permanesca asî" (Obligación de dorado del retablo mayor del Colegio de San Basilio por Miguel Delgado Moreno. AHPS, Secc. Protocolos Notariales, leg. 9548, ff. 303r-304v). He aquí sus condiciones técnicas: “...lo e de dorar en esta manera: la talla, molduras y lisos de mague, de color verde, encarnado y asul, y sobre dicho mague en aquellas partes principales y más manifiestas sus lavores de plata bañada de corladura de modo que paresca propio oro y que siempre permanesca así, y dichas lavores de plata an dir perfiladas i en tales y quales partes como son tanvanillos, y en algunas partes mayores se plateará y bañará de ultramar formando en estas partes mayores unas piedras..."

${ }^{46}$ Las medidas de estas dos pinturas no se corresponden con las requeridas para el banco en el contrato de Fernando de los Ríos ("los que an de estar al pie del altar an de tener, de guecos, de alto una bara menos dos dedos y de ancho dos tercias", es decir: unos 82 x $55 \mathrm{~cm}$ ); creo que se debe al hecho de que se encuentren integradas en el marco arquitectónico del primer cuerpo del sagrario, cuyas columnas sí que tenían una vara de altura.
} 
Figura 3. San Basilio el Mayor, padre de San Basilio.

Figura 4. Santa Eumelia, madre de San Basilio.
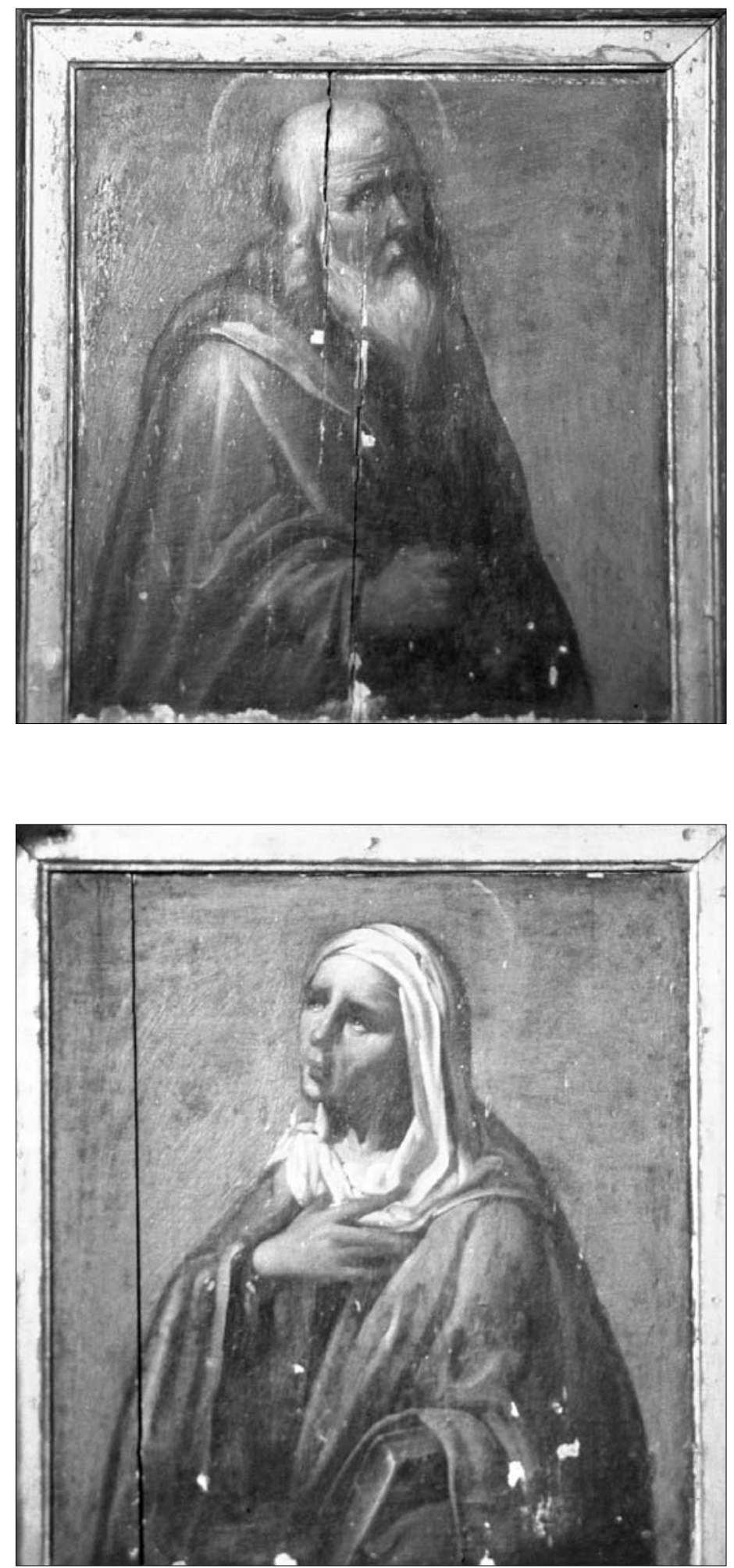

AEA, LXXIX, 316, OCTUBRE-DICIEMBRE, 355-370, 2006, ISSN: 0004-0428 
la diestra se apoya sobre su pecho; también tiene halo de santidad y dirige su vista hacia arriba (fig. 4$)^{46}$.

Todos los elementos de la iconografía de estas pinturas remiten a una procedencia basiliana de las mismas. El Niño Jesús, revestido del hábito basilio, es una buena muestra de esa tradición que, al menos desde el siglo XVII hasta nuestros días, acostumbra a presentarlo —en algunas pinturas, pero sobre todo esculturas - con ropajes de distinta índole que dependen de las variadas devociones populares a las que se adaptan las imágenes (por ejemplo: de cardenal, jesuita, pastor, etc.).

La pareja de ancianos representan a los padres de San Basilio: Santa Eumelia y San Basilio el Mayor. Su colocación a ambos lados del sagrario, en una privilegiada posición jerárquica, asî parece confirmarlo, si tenemos en cuenta que el resto de las pinturas que se sabe existían en el banco del retablo eran los respectivos abuelos maternos y paternos del santo, que, lógicamente, se situarían simétricamente por parejas a ambos lados del mismo. El anciano con su bastón no parece tener otro atributo que la propia bondad de su rostro y el halo de santidad que rodea su cabeza. Según los autores que tratan de la vida del padre de San Basilio, éste era un hombre "de lo más noble y autorizado del Ponto" que, junto a su esposa, eran los más ricos de la región de Capadocia y Armenia Menor; y que, a sus "grandes haciendas", añadían "el thesoro de todas las virtudes". De Eumelia, la madre de San Basilio, se dice que educó a sus hijos en la afición a los libros de la Sagrada Escritura, singularmente a su hija Macrina. Ambas fundaron un monasterio que seguía la regla de San Basilio, del que Macrina fue Abadesa. Es muy posible que el libro con el que se la representa en la pintura este relacionado con su labor educadora de sus hijos y con el carácter de cofundadora de la rama femenina del monacato basilio ${ }^{47}$.

Estilísticamente, es de subrayar la calidad homogénea de las tres obras, a diferencia de lo que ocurre con las pinturas de los hermanos de San Basilio, donde las diferencias son notables. La pincelada es precisa y decidida, como en las mejores obras de Herrera el Viejo; también es muy característica del maestro la gama de colores utilizada. Las representaciones de ambos ancianos recuerdan en su composición y rasgos a las de los padres de la Virgen en el lienzo que se conserva en una colección particular de la Inmaculada con San Joaquín y Santa Ana ${ }^{48}$. El Niño Jesús, único que se conoce de este pintor, es de una gran belleza y elegancia compositiva; su melancólica mirada es el contrapunto de las enérgicas figuras que pueblan otras pinturas del primitivo retablo y sobre las que se ha cimentado la fama de Francisco Herrera el Viejo.

Recibido: 5-IX-2005

Aceptado: 10-X-2005

\footnotetext{
${ }^{47}$ Fr. Francisco de BéJar: Historia de la vida de S. Basilio el Grande, Doctor de la Iglesia, Arzobispo de la Cesárea, Capadocia, Fundador y Patriarca de los Monges, Madrid, 1736, pp. 6-7 y 11-12.

48 El lienzo Inmaculada con San Joaquín y Santa Ana, de colección particular, está reproducido en el artículo citado de Pérez Sánchez y Navarrete Prieto (1996, pp. 377-378, fig. 24).
} 